\title{
Administração Internacional do Estado
}

\author{
Eduardo Lobo Botelho Gualazzi \\ (Professor Assistente-Doutor de Direito Administrativo \\ na Faculdade de Direito da USP. Procurador do \\ Estado de São Paulo) \\ (Doutor em Direito pela FADUSP)
}

\begin{abstract}
S U M A R I O : 1. Introduçáo. 2. Autonomia científica das disciplinas juridicas. 2.1. Autonomia cientifica do Díreito Administrativo $\Theta$ do Direito Internacional Público. 2.2. Objetos interdisciplinares. 3. Direito Administrativo Internacional e Direito Internacional Administrativo. 3.1. Método comparativo. 4. Admin̄istração Internacional do Estado. 4.1. Definição. 4.2. Regime jurídico interdisciplinar. 4.3. Taxinomia na Administraç̃o Pública. 4.4. Relações administrativas com a Administração Internacional. 5. Conclusões.
\end{abstract}

\section{1 - Introdução}

Nossa concepção de Administração Pública é a seguinte: I) Administração Internacional: a) Administração exterior (organismos administrativos internacionais) ; b) Administração interior (organização administrativa interna das entidades e órgãos internacionais); II) Administração Interna ou Estatal: a) Administração Direta ou Centralizada; b) Administração Indireta ou Descentralizada; c) Administração Infradireta ou Pericêntrica (Administração Sócio-Econômica e Administração Interestatal) (cf. nosso Serviços Comerciais, Industriais e Internacionais do Estado, 1985, São Paulo, Editora Revista dos Tribunais, p. 77).

Por outro lado, o Estado projeta-se e atua, na área internacional, por meio de relações jurídico-soberanas de coordenação, regidas pelo Direito Internacional Público, bem como por redações jurídico-administrativas de integração, sob a égide do Direito Administrativo Internacional. A Administração Internacional do Estado abrange, assim, a parcela de atividades administrativas estatais que efetivam, in concreto, as relações políticas e jurídicas do Estado, na área internacional, seja como Estado-soberania (sob a regência do Direito Internacional Público), seja como Estado-Administracão (sob a égide do Direito Administrativo Internacional, capitulo do Direito Administrativo). O relacionamento político-jurídico do Estado-soberania, na área internacional, cabente ao Direito Internacional Público, remanesce alheio ao presente estudo. Analisar-se-á, porém, o relacionamento administrativo integrante do Estado-Administrậ̃a, na área internacional, por- 
quanto sofre a incidência do Direito Administrativo, marcadamente do Direito Administrativo Internacional.

$\mathrm{O}$ relacionamento administrativo integrante do Estado-Administração, na área internacional, insere-se no âmbito da Administração Infradireta ou Pericêntrica, como Administração Interestatal. Nos aspectos principiológico e de regime jurídico, subsume-se a duas disciplinas jurídicas: Direito Administrativo e Direito Internacional Público. Verifica-se, pois, que o relacionamento administrativo integrante do Estado-Administração, na área internacional, consiste em tema, em objeto interdisciplinar, como outros na Ciência do Direito, a suscitar exame prévio das próprias zonas de intersecção entre as disciplinas jurídicas cientificamente autônomas, assinaladamente entre o Direito Administrativo e o Direito Internacional Público.

\section{Autonomia Científica das Disciplinas Jurídicas.}

A Ciência do Direito constitui uma unidade especializada de cognição, sob aspectos formal e material, no âmbito das ciências sociais, caracterizadas pelo princípio da sociabilidade. A unidade da Ciência do Direito é assegurada por princípios monovalentes, válidos somente para esta província da cultura humanística. Portanto, consiste em truísmo afirmar-se que há interligação lógica, necessária, entre todos os ramos da Ciência do Direito. Com efeito, todos os ramos da ciência jurídica nutrem-se da seiva comum, consistente nos princípios jurídicos monovalentes.

«Por sua vez, todos os ramos da ciência jurídica, uns de recente formação, outros de tradicional existência, com objeto próprio, método próprio e princípios informatives próprios, proclamam sua autonomia, necessitando, porém, de um reexame crítico da problemática principiológica setorial, para que se firmem na análise do regime jurídico dos respectivos institutos, sempre em conexão com as categorias jurídicas, momento anterior de generalidade que se ergue no vestibulo de cada ramo» (José Cretella Júnior, Trấado de Direito Administrativo, vol. X, 1972, Rio, Forense, p. 32)

A autonomia científica das disciplinas juridicas fundamenta-se, pois, em objeto próprio, método próprio e princípios informativos próprios.

Entretanto, não se pode obscurecer a evidência de que subsiste, a nível teorético e prático, uma tensão dialética entre os atributos autonômicos das disciplinas jurídicas e os atributos monovalentes da Ciência do Direito. A preocupação permanente de edificar ou manter-se a autonomia diferencial das disciplinas jurídicas (tese) provém da resistência contínua à força centrípeta, uniformizadora, dos princípios jurídicos monovalentes (antítese), que resulta nas alterações de limites disciplinares e nas crescentes interseccões entre as disciplinas jurídicas (síntese). 
Os lindes entre as disciplinas jurídicas não passam de pontos lógico-referenciais em efetiva ou potencial evolução, porquanto os objetos próprios dos ramos jurídicos mesclam-se em velocidade montante, ante o dinamismo dos fatos sócio-jurígenos. Os métodos próprios de análise, de cada disciplina jurídica, tendem a uniformizarem-se, à medida que, em cada ramo do Direito, se busca partir indutivamente dos institutos específicos para atingir-se categorias jurídicas, as «formas puras do Direito», comuns a várias disciplinas jurídicas.

Os princípios setoriais próprios de disciplina jurídica, ademais, constituem somente especializaçōes dos princípios jurídicos monovalentes, voltados especificamente para o objeto próprio de cada disciplina.

Em conseqüência, pode-se concluir que a autonomia científica das disciplinas jurídicas constitui uma construção teorética in fieri, em evolução lentíssima, mas perpétua a inexorável, cujo único aspecto sólido e definitivo consiste na possibilidade de alteração. Longe de consistir em sedimentação pétrea e estática de compartimentos estanques, a autonomia científica das disciplinas jurídicas mais parece um sistema lógico de vasos intercomunicantes, por onde se distribuem dinamicamente os fatos sócio-jurígenos, à busca da valorização que os enquadre numa disciplina jurídica ou, como objetos interdisciplinares, em duas ou várias disciplinas jurídicas.

Entre as disciplinas jurídicas, sobretudo as do Direito Público, aumentam inexoravelmente as zonas secantes, as áreas comuns, os objetos interdisciplinares, bem como a aplicação intra e interdisciplinar do método comparativo. No Direito Público, proteiforme e evolutivo por excelência, agigantam-se incoercivelmente as interconexões jurídico-científicas entre o Direito Interno e o Internacional, corolário da explosiva internacionalização do mundo contemporâneo, fenômeno sócio-jurígeno que nenhum jurista pode ignorar.

As áreas de Direito do Estado e de Direito Internacional aproximam-se celeremente, sob aspectos teórico e prático. Em algumas Universidades estrangeiras, já consistem de área única, com salutar convivência das respectivas disciplinas jurídicas, posto serem todas facetas diferenciadas da atuação do Estado: talvez esta realidade estrangeira também se concretize, num futuro distante, na Faculdade de Direito da Universidade de São Paulo, sempre sensível à evolução cientifica internacional.

\subsection{Autonomia científica do Direito Administrativo e do Direito In- ternacional Público.}

A autonomia científica do Direito Administrativo provém de reunir esta disciplina jurídica objeto próprio, método próprio e princípios informativos próprios.

O objeto próprio do Direito Administrativo é o conjunto de atividades das pessoas jurídicas públicas e a instituição de meios e órgãos relativos à ação dessas pessoas. 
Outrossim, vários são os métodos possiveis, na Ciência do Direito. Assim, assinalam-se, verbi gratia, os métodos exegético, sociológico, "a priori», "a posteriori», realista, dogmático e jurídico (cf. José Cretella Júnior, Tratado de Direito Administrativo, vol. I, 1966, Rio/São Paulo, Forense, p. 379).

Consiste o método jurídico em analisar o conteúdo de cada sistema positivo para produzir sua unidade. Baseando-se na razão, procura demonstrar que a ciência jurídica deve ser racional em seu desenvolvimento, porque sua elaboração há de consistir na dedução das conseqüências que derivam dos princípios normativos positivos. Se direito público é uma disciplina jurídica, necessário aplicar-lhe o método jurídico, que compreende duas partes essenciais: a análise jurídica e a construção jurídica, consistindo a primeira na investigação dos princípios e procurando a segunda extrair destes todas as conseqüências (cf. José Cretella Júnior, Tratado de Direito Administrativo, vol. I, 1966, Rio/São Paulo, Forense, p. 379).

O método jurídico, no âmbito do Direito Administrativo, abrange duas dimensões. Em primeiro lugar, aplicação de indução e dedução, para extrair-se do jus positum, da jurisprudência judiciária e dos fenômenos jurígenos in genere (o denominado «direito à margem») o conjunto de princípios setoriais disciplinares (indução), para posteriormente, por analogia ou extensão, abarcar nos princípios os casos concretos não previstos (dedução). A segunda dimensão consiste na aplicação da análise diacrônica - História do Direito — e da síntese sincrônica - Direito Comparado, método comparativo - , para atingirem-se os limites extremos (formais e substanciais) do Direito Administrativo, bem como as intersecções e áreas comuns com outras disciplinas jurídicas.

Os princípios informativos próprios do Direito Administrativo são os de: a) hierarquia; b) prerrogativas públicas; c) especialidade; d) continuidade; $e$ ) igualdade do administrado; f) presunção da verdade; g) tutela administrativa; h) indisponibilidade do interesse público; i) poder-dever do administrador (cf. José Cretella Júnior, Tratado de Direito Administrativo, vol. X, 1972, Rio, Forense, p. 34-144).

Por outro lado, o Direito Internacional Público igualmente consiste em disciplina jurídica cientificamente autônoma, com objeto próprio, método próprio e princípios informativos próprios.

O objeto próprio do Direito Internacional Público é o conjunto das relações político-jurídicas internacionais do Estado-soberania e de outras pessoas, entidades e órgãos, dotados de alguma espécie de personalidade internacional.

O método próprio do Direito Internacional Público soe consistir numa combinação entre os métodos jurídico, realista e sociológico, sem exclusão de ocasional aplicação de outros métodos. Assim, o Direito Internacional Público analisa diretamente fatispécies internacionais, de 
natureza pública, extraindo-lhes a essência jurigena e atribuindo-lhes valoração política, sociológica e jurídica, numa metodização indutiva que conduz aos princípios setoriais e às «normas fundamentais» desta disciplina, dedutivamente estendidas, a posteriori, por analogia ou ex aequo et bono, a casos concretos ou lacunas do jus positum internacional.

Os princípios informativos próprios do Direito Internacional Público são os do consentimento, reciprocidade, igualdade dos Estados, finalidade das decisões judiciais e arbitrais, validade legal dos acordos, boa-fé, jurisdição estatal, liberdade dos mares, proibição à guerra agressiva, interdição ao genocídio, não-discriminação racial, proibição de crimes contra a humanidade e proibição à pirataria e ao comércio de escravos. Embora não exauram o rol de princípios setoriais do Direito Internacional Público, estes treze princípios são considerados pacíficos, não controvertidos (cf. Ian Brownlie, Principles of Public International Law, third edition, 1984, Oxford, Clarendon Press, p. 19 e 513).

\subsection{Objetos interdisciplinares.}

$\mathrm{Na}$ Ciência do Direito, assinala-se a existência de vários objetos interdisciplinares, consistentes de fatos do mundo ou de categorias jurídicas que, no mundo do Direito, são valorados, normatizados e recebem atributos diferenciais no âmbito próprio de duas ou mais disciplinas jurídicas.

Por outro lado, no âmbito específico de qualquer disciplina jurídica sempre subsiste a possibilidade de alguma instituição ou instituto típico de tal disciplina produzir um efeito jurídico, puramente episódico e incidental, em outra disciplina. Assim, verbi gratia, os efeitos da condenação criminal definitiva na área do Direito Administrativo Disciplinar. Tais instituições e institutos regem-se, porém, pelos métodos próprios e princípios informativos próprios de suas respectivas disciplinas jurídicas, com exclusividade, mesmo quando geram efeitos circunstanciais em outras disciplinas jurídicas.

Os objetos interdisciplinares, todavia, distintos das instituições e institutos típicos das disciplinas jurídicas, remanescem sempre e inexoravelmente abrangidos pelos métodos próprios e princípios setoriais próprios de duas ou mais disciplinas jurídicas. Assim, verbi gratia, o objeto interdisciplinar Liberdades Públicas, considerado pela doutrina brasileira e estrangeira como «disciplina-encruzilhada» (cf. José Cretella Júnior, Liberdades Públicas, 1974, São Paulo José Bushatsky, Editor, p. 25), é abrangido pelos métodos próprios e princípios informativos próprios de todas as disciplinas jurídicas públicas e privadas, com predominância dos Direitos Constitucional, Administrativo e Internacional Público (este último na área dos Direitos Humanos).

No tocante à atividade jurídico-constitucional do Estado, igualmente há, efetiva ou potencialmente, objetos interdisciplinares, regi- 
dos pelo Direito Constitucional e pelo Direito Internacional Público, aspecto que conduziu Georg Dahm a observar o seguinte: «todo que é objeto do Direito nacional - sem excluir-se, por exemplo, a própria Constituịção do Estado - pode efetivamente ser, ou chegar a ser, objeto do Direițo Internacional Público» (Völkerrecht, vol. I, Stuttgart, 1958, § 1, p. 3).

Irrecusável, porém, que o objeto interdisciplinar mais tradicional da Ciência do Direito consiste das atividades administrativas internacionais do Estado - a administragão internacional do Estado -, predominantemente abrangidas por duas disciplinas jurídicas: Direito Administrativo (especialmente Direito Administrativo Internacional) e Direito Internacional Público (especialmente Direito Internacional Administrativo).

\section{Direito Administrativo Internacional e Direito Internacional Ad- ministrativo.}

Elucida José Cretella Junior que «setor algum dos conhecimentos humanos constitui círculo fechado e incomunicável de noções. Toda disciplina científica e, mais ainda, filosófica, mantém conexões com outros setores do saber, estabelecendo-se uma relação contínua de dependêneia recíproca, relação esta de reciprocidade e subordinação, característica extraordinária do saber humano. (...) Ora, ciência jurídica, por excelência, como é, mantém no direito administrativo conexões intimas com as demais disciplinas jurídicas, quer no âmbito do direito público (direito constitucional, direito processual, direito penal, direito internacional público), quer no âmbito do direito privado (direito civil, direito comercial, direito internacional)» Tratado de Direito Administrativo, vol. I, 1966 Rio/São Paulo, Forense, p. 185-186).

Na Ciência do Direito, o Direito Administrativo é a disciplina jurídica mais receptiva e porosa a elementos oriundos de todas as outras disciplinas jurídicas e de algumas disciplinas extrajurídicas, atinentes a várias áreas humanísticas e exatas da cultura científica. Este característico do Direito Administrativo deriva do fato de que esta disciplina jurídica normatiza o funcionamento, a dinamização concreta da Administração Pública, que é forçada a lidar, na diarística administrativa, com fatispécies jurígenas, internas e internacionais, que refletem a incidência de institutos, instituições e regimes jurídicos de outras disciplinas jurídicas.

Por esse motivo, afirma Stei que o Direito Administrativo se relaciona com todos os ramos do saber humano e, mais, que retira de outras ciências seu conteúdo, sendo, no entanto, original e autônomo no sentido de que o retira de maneira particular para aplicá-lo a fim distinto e prốprio (cf. J. Guimarães Menegale, Direito Administrativo e Ciência da Administração, $3^{\text {a }}$ ed., 1957, Rio de Janeiro, Borsoi, p. 11). 
Assim, verifica-se a crescente interconexão entre o Direito Administrativo e o Direito Internacional Público. A área comum a ambas as disciplinas jurídicas dilata-se e solidifica-se de modo irreversível, como resultado da montante integração administrativa internacional (cf. nosso Servicos Comerciais, Industriais e Internacionais do Estado, 1985, São Paulo, RT, p. 68-74 e 124-131).

$\mathrm{Na}$ literatura administrativa brasileira, a relevância do tema foi realçada pela primeira vez, em 1966, por José Cretella Júnior, de modo incisivo e veemente: "a intensa vida de relação entre os Estados modernos deu origem, na órbita internacional, ao aparecimento de inúmeros vínculos, jurídicos e sociais, que, ao serem apreciados de maneira científica, passam pelo crivo de princípios do direito internacional público através de órgãos e agentes que se submetem a normas ditadas pelo direito administrativo. $\mathrm{E}$, tão freqüentes e importantes são os pontos de contato que surgem entre esses ramos do Direito, que, em torno da nova disciplina, por alguns denominada de direito internacional administrativo e por outros de direito administrativo internacional, floresceu copiosa bibliografia especializada em que primam, pela excelência e clareza, os trabalhos de internacionalistas e de administrativistas italianos. Muitos dos problemas, a princípio afetos às Administrações locais, pelos característicos gerais de universidade de que se revestem, passam a projetar-se na órbita internacional, despertando o interesse simultâneo de vários países que procuram de comum acordo resolvê-los. Vem desse modo o direito internacional em socorro da Administração e, de acordo com os princípios deste, encontram-se os meios adequados para a resolução exata dos assuntos de interesse coletivo. Por sua vez, o direito administrativo, instituindo órgãos e meios de ação na esfera internacional, estabelecendo princípios para regular os servicos públicos internacionais, facultando aos agentes credenciados a solução dos problemas que interessam a vários países, projeta-se além das fronteiras locais e integra-se num plano universal» (José Cretella Júnior, Tratado de Direito Administrativo, vol. I, 1966, Rio/São Paulo, Forense, p. 195-196, grifos nossos).

Verifica-se que José Cretella Júnior não hesitou em considerar o Direito Internacional Administrativo ou Direito Administrativo Internacional como «nova disciplina», assim atribuindo-lhe, expressamente, autonomia científica em relação ao Direito Administrativo e ao Direito Internacional Público. Por outro lado, o Professor José Cretella Junior não distingue, cientificamente, entre Direito Administrativo Internacional e Direito Internacional Administrativo.

Assim como o Direito Urbanístico encontrava-se, muitos anos atrás, como disciplina in fieri, na Ciência do Direito, sendo sua autonomia científica ainda acerbamente criticada, no momento atual, tambẻm a Direito Administrativo Internacional é uma disciplina jurídica in fieri, que somente alcançará autonomia científica em futuro distante. No momento atual, a matéria atinente ao Direito Administrativo Internacional (assim como a relativa ao Direito Internacional Administrativo) ainda constitui um objeto interdisciplinar. 
Com efeito, há um objeto interdisciplinar, entre o Direito Administrativo e o Direito Internacional Público, consistente no serviço público estatal com destinação internacional e no serviço público internacional com destinação estatal, além de áreas específicas do Direito Internacional Público que aplicam Direito Administrativo (sobretudo Direito Administrativo Disciplinar) e áreas do Direito Administrativo que aplicam o Direito Internacional Público e, por exceção, o Direito do Comércio Internacional (de natureza privatística).

Os métodos próprios do Direito Administrativo e do Direito Internacional Público assemelham-se e virtualmente identificam-se, em vista de trabalharem com fenômenos administrativos caracterizados por crescente entrelaçamento.

Por outro lado, há uma essência comum entre os princípios informativos do Direito Administrativo e do Direito Internacional Público, consistente no princípio da integração sistêmica da administração, que se enuncia como a necessidade de incutir-se nos entes administrativos a consecução dos fins do aparelhamento administrativo do Estado, para assegurar-se o fluxo harmônico e unidirecional das atividades administrativas públicas, internas e internacionais (cf. nosso Serviços Comerciais, Industriais e Internacionais do Estado, 1985, São Paulo, RT, p. 33).

A propósito do tema, é mister atentarmos ao magistério de José Gascon Y Marin, que foi Professor de Direito Administrativo e de Direito Internacional Público: «a extensão do domínio do Direito Administrativo, assim como o das relações internacionais, tornando-se cada dia maior, é tanto mais necessário erigir como ramo científico autônomo o estudo dos problemas jurídicos colocados pela realização de um fim determinado: a ação administrativa internacional. Assim como atualmente o Direito Administrativo diferencia-se do Direito Político ou Constitucional, a partir da diferença evidente entre Constituição e Administração, no Direito dos Estados que constituem o que denominamos de Sociedade internacional, da mesma diferença nascerá um Direito Internacional Administrativo, pois, mesmo supondo-se muito imperfeita a Sociedade internacional, não se pode negar que não somente ela se constitui, mas age, vive, desenvolve uma atividade especial, e nesta ação e nesta vida, nesta realização de seus fins particulares, distintos daquelas do Direito Público Internacional, na necessidade de criar para si órgãos à realização dessas finalidades, na de conservar e aperfeiçoar seus órgãos, para concretizar os fins para os quais foram criados, encontramos uma atividade administrativa internacional que necessita de regras jurídicas, de um Direito que se desenvolverá progressivamente cada dia» (José Gascon Y Marin, Les Transformations du Droit Administratif International, in Recueil des Cours de l'Académie de Droit International de la Haye, 1930, IV, tome 34 de la Collection, Sirey, p. 21-22, (grifos nossos).

A previsão de José Gascon $\mathrm{Y}$ Marin, expressa em 1930, concretizou-se parcialmente. Verbi gratia, em 1968, Carlos Garcia e Enrique 
Martinez Uzeros assinalavam a publicação de centenas de artigos e opúsculos sobre Direito Administrativo Internacional e Direito Internacional Administrativo, assim como dos livros de Umberto Fragola, Diritto Amministrativo Internazionale ( $3^{\text {a }}$ ed., Napoli, 1951), e de Biscotini, Diritto Amministrativo Internazionale (vol. I, Padova, 1964) (cf. Carlos Garcia Oviedo e Enrique Martinez Useros, Derecho Administrativo, 9a ed., vol. III, 1968, Madrid, EISA, p. 9-15).

No Brasil, paradoxalmente, reinou o mais profundo silêncio, sobre Direito Administrativo Internacional e Direito Internacional Administrativo, até 1966, quando José Cretella Júnior pioneiramente suscitou o tema numa passagem de seu Tratado de Direito Administrativo (vol. I, 1966, Rio/São Paulo, Forense, p. 195-196), já transcrita neste artigo.

A partir da premissa assentada por José Cretella Júnior, em 1966, incluímos em nossa obra Serviços Comerciais, Industriais e Internacionais do Estado (São Paulo, 1985, RT) um estudo mais alentado sobre Direito Administrativo Internacional e Direito Internacional Administrativo, embora este tema haja comparecido, em nosso livro, de modo meramente subsidiário, a fim de compor a análise do tema central da obra: administração atípica do Estado.

Em nossa obra, partimos do magistério de José Cretella Júnior, bem como de Carlos Garcia Oviedo e Haroldo Valladão.

Explicita Carlos Garcia Oviedo que «existem, pois, duas classes de Administração: a Administração da sociedade internacional como realidade orgânica e a Administração dos Estados particulares no âmbito internacional. No aspecto orgânico, traduz-se esse dualismo na existência: a) de uma organização administrativa internacional, e b) de uma organização administrativa interior para os assuntos internacionais. Situando esta matéria em um plano jurídico, cabe distinguir entre um Direito Internacional Administrativo e um Direito Administrativo Internacional. $E$ aquele um Direito regulador das relações derivadas da existência de uma sociedade internacional. Corresponde ao organismo internacional e brota dele (Sociedade das Nações, Uniões, (ONU). O estudo deste ordenamento constitui o Direito Internacional. O Direito Administrativo Internacional regula a atividade do Estado endereçada à realização de seus fins além de suas fronteiras nacionais - comércio internacional, movimento demográfico, proteção aos súditos do país. É um Direito interno, projetando-se no Exterior» (Carlos Garcia Oviedo, Derecho Administrativo, 3 ed., Madrid, EISA, 1951, p. 613-614).

Esclarece Haroldo Valladão: «em especial para as leis administrativas, desenvolvimento e complemento das leis constitucionais, vai haver na doutrina mundial uma evolução acerca das expressões, Direito Administrativo Internacional e Direito Internacional Administrativo, considerando-se constituir a primeira um ramo do DIP, conflito das leis administrativas, e a segunda um ramo do Direito Inter- 
nacional Público, Direito das organizações internacionais. (. .) A concepção de um Direito Administrativo Internacional se materializa, esplendidamente, na obra do seu verdadeiro fundador, Karl Neumayer, em cinco volumes, I, II, III, II-2 e IV, 1910-1936 (cf. H. Valladão, O Ensino o o Estudo do Direito. ., p. 94) salientando ele a inspiração recebida de Von Bar, desde 1893, declarando em sua tese de docentelivre, de 1907, que «o Direito Administrativo Internacional é um novo ramo a se desenvolver do DIP» (vol. IV/I) «e versando os limites da administração pública de um Estado em confronto com as de outro Estado» (Haroldo Valladão, Direito Internacional Privado, vol. III parte especial, Rio/São Paulo, Freitas Bastos, 1978, p. 287).

Partimos desses magistérios para considerar que, no tocante ao objeto, o Direito Administrativo Internacional é um ramo tridisciplinar do Direito Público, com a seguinte dicotomia de objeto: a) conflito de leis administrativas estatais entre Estados (formalmente atinente ao Direito Internacional Privado; materialmente, ao Direito Administrativo interno); b) integração coordenante de relações administrativas internacionais de serviço público, entre Estados e organismos internacionais (formalmente atinente ao Direito Internacional Público; materialmente, ao Direito Administrativo Internacional, capítulo do Direito Administrativo interno) (cf. nosso Servicos Comerciais, Industriais \& Internacionais do Estado, 1985, São Paulo, RT, p. 125).

Consideramos o Direito Administrativo Internacional como o capítulo do Direito Administrativo que rege juridicamente o serviço público-administrativo integrante do Estado, com destinação internacional. E consideramos o Direito Internacional Administrativo como o capítulo do Direito Internacional Público que rege juridicamente a atividade administrativa internacional, tanto a relativa à organização interior dos órgãos e entidades internacionais, como a dirigida à coordenação de serviços públicos estatais. Embora ainda constituam capítulos de duas disciplinas jurídicas tradicionais (Direito Administrativo e Direito Internacional Público), ambos já regem objeto interdisciplinar comum, têm métodos virtualmente idênticos e conectam-se por um princípio setorial comum, o principio da integração sistêmica da Administração. Assim, tudo concorre para fortalecer o prenúncio de José Cretella Júnior, no sentido de que «nova disciplina» se encontra in fieri, em vias de paulatina formação. Data venia, não pouparemos esforços para contribuir à formação gradativa dessa «nova disciplina», em pesquisas futuras.

\section{1 - Método comparativo.}

A análise do Direito Administrativo Internacional e do Direito Internacional Administrativo remanescerá sempre fundamentada numa aplicação especial do Direito Comparado, do método comparativo.

«O direito comparado, como se sabe, não é ramo da árvore do direito. Não é disciplina jurídica, autônoma. Não é direito. É método 
científico que, recorrendo à' observação e ao cotejo, ressalta os traços dominantes de vários sistemas jurídicos, confrontando, no mesmo plano, institutos paralelos e sistemas, para depois concluir pela universidade de um conceito ou pela tipificação de um instituto num dado sistema de direito. É a comparação dos direitos. É o método comparativo aplicado ao setor da ciência jurídica. Por isso, é inexato falar em regras de direito comparado, como é incorreto mencionar normas de direito comparado. $O$ método comparativo pode ter abrangência máxima, transcendendo a ala do direito público e do direito privado para trabalhar em esfera categorial e pode descer a cada um dos ramos tradicionais do direito e confrontá-lo no que ele tem em comum» (José Cretella Júnior, Direito Administrativo Comparado, 1972, São Paulo, EDUSP, p. 24).

A aplicação especial do método comparativo, em Direito Administrativo Internacional e Direito Internacional Administrativo, consiste em trabalhar-se, num primeiro momento, na região categorial comum ao Direito Administrativo e ao Direito Internacional Público (serviço público; atos e contratos administrativos, órgãos administrativos; justiça administrativa interna e internacional, inclusive disciplinar; domínio público, e outras categorias), para lograr-se, em momento final de síntese, a fixação do regime jurídico e dos atributos diferenciais dos institutos e instituições, na área estatal e na internacional. Assim como o método comparativo é tradicionalmente aplicado no confronto de Direitos nacionais e de sistemas jurídicos, também pode ser utilizado no confronto entre o Direito Administrativo e o Direito Internacional Público (e, por exceção, o Direito Internacional Privado).

Esta aplicação especial do método comparativo constitui tarefa dificílima e espinhosa, que exige conhecimento profundo de Direito Administrativo e de Direito Internacional Público, além de outras qualificações. Ao que saibamos, não existe, na literatura jurídica, brasileira ou estrangeira, obra que verse o Direito Administrativo Internacional e o Direito Internacional Administrativo sob o enfoque do método comparativo. Eis cá, porém, uma obra que precisa ser escrita, com a possivel brevidade.

\section{4. - Administração Internacional do Estado.}

A Administração Internacional do Estado constitui-se de todos os órgãos e atividades administrativas internas do Estado destinados à área internacional ou receptadores do serviço público internacional. Rege-se, lato sensu pelo Direito Público, que somente para fins didáticos e metodológicos bifurca-se em Direito Público Interno e Direito Público Internacional ou Direito Internacional Público, embora as relações internacionais públicas do Estado não esgotem o conteúdo do Direito Internacional Público.

A propósito, observou José Gascon Y Marin: «a Administração não foi concebida somente como enclausurada no círculo da vida interna 
dos Estados; ao contrário, dada sua atividade no campo das relações internacionais, foi preciso distinguir a Administração interna e a Administração externa. Contudo, os autores de tratados de Direito Administrativo não estudaram todos esta derradeira forma, pois, atendo-se ao estudo do Direito Público interno, por isto circunscreveram nos mesmos limites o exame da administração do ponto de vista jurídico» (Les Transformations du Droit Administratif International, in Recueil des Cours de l'Académie de Droit international de La Haye, IV, tome 34, Sirey, 1930, p. 7).

Após meio século, aquela situação comentada por José Gascon $Y$ Marin permanece virtualmente inalterada. A maioria dos autores de Direito Administrativo ainda concentra sua atenção mais apurada no Direito Administrativo interno e na Administração Pública interior. No Brasil, conforme já se frisou, apenas um administrativista, José Cretella Júnior, dedicou um capítulo de sua obra às relações administrativas internacionais do Estado e ao Direito Administrativo Internacional (cf. José Cretella Júnior, Tratado de Direito Administrativo, vol. I, 1966, Rio/São Paulo, Forense, p. 195-196), sendo certo que, no Brasil, outros administrativistas nunca se pronunciaram sobre o tema. Aliás, no Brasil, tampouco os especialistas em Direito Internacional Público manifestaram-se sobre a matéria, talvez por considerá-la primordialmente afeta aos estudiosos do Direito Administrativo. Existem apenas, na literatura estrangeira, muitos artigos, poucos opúsculos e raríssimos livros, a respeito do assunto, aspecto já suscitado item 3 deste artigo, atinente a Direito Administrativo Internacional e o Direito Internacional Administrativo.

Por outro lado, definimos Administração Pública como o organismo executor da atividade estatal e interestatal, que assegura a integração coordenada, interna e internacional, da gestão especializada e técnico-científica do serviço público-administrativo, para consecução permanente e ininterrupta das necessidades, conveniências e interesses públicos.

Optamos, portanto, consoante nossa definição, por uma concepção latíssima, global e universalista de Administração Pública, considerada como organicidade estatal e interestatal, destinada à consecução do interesse público interno e externo, para satisfação das necessidades coletivas nacionais e internacionais, em consonância com a indeclinável inserção do Estado no concerto da comunidade universal, composta apenas pela soberania dos Estados, mas igualmente pela autonomia derivada de organismos administrativos internacionais e outras entidades, internacionais e transnacionais (públicas, privadas ou mistas), de cunho administrativo, técnico-científico e especializado (cf. nosso Serviços Comerciais, Industriais e Internacionais do Estado, 1985, São Paulo, RT, p. 60).

A Administracão Internacional do Estado consiste na parcela especializada da Administração Pública, cuja finalidade é a manutenção das relações administrativas internacionais do Estado, para a conse- 
cução do interesse público interno e externo e satisfação das necessidades coletivas nacionais e internacionais.

\section{1 - Definição.}

Sob aspecto formal, define-se Administração Internacional do Estado como o conjunto de órgãos, entidades e agentes públicos que realizam as relações administrativas internacionais do Estado.

Sob aspecto substancial, define-se Administração Internacional do Estado como o complexo de atividades jurídico-administrativas de integração internacional do Estado.

Combinando-se os critérios formal e substancial, define-se Administração Internacional do Estado como o conjunto de entidades, órgãos e agentes públicos estatais que concretizam as atividades e relações jurídico-administrativas de integração interestatal.

\section{2 - Regime jurídico interdisciplinar.}

A Administração Internacional do Estado rege-se, primacialmente, pelo Direito Administrativo (especialmente pelo Direito Administrativo Internacional) e pelo Direito Internacional Público (especialmente pelo Direito Internacional Administrativo).

Ouçamos José Gascon Y Marin: «as relações internacionais supõem serviços administrativos. $E$ ao Direito Administrativo que pertence $o$ estudo da organização administrativa deste serviço (Ministério das Relações Exteriores, carreiras diplomática e consular). O Estado, a fim de manter sua personalidade internacional, tem necessidade de ser independente, de estabelecer reláções com os outros Estados, defendendo seus interesses nacionais fora do território. A armada é a instituição nacional encarregada de defender a independência do Estado. Ingressa no Direito Administrativo aquilo que, nas Missões e Escritórios Internacionais, possa interessar ao Estado. O Estado participa da vida internacional. Há serviços administrativos e princípios jurídicos que regem esta participação» (José Gascon Y Marin, Les Transformations du Droit Administratif International, in Recueli dos Cours de l'Academie de Droit International de La Haye, 1930, IV, tome 34 de la Collection, Sirey, p. 12).

A Administração Internacional do Estado consiste, na verdade, em objeto interdisciplinar, cujo regime jurídico assenta-se nos métodos próprios e princípios informativos próprios do Direito Administrativo e do Direito Internacional Público.

\section{3 - Taxinomia na Administração Pública.}

No momento presente, no Direito positivo em vigor, a Administração Pública Federal do Brasil apresenta o seguinte perfil institucional: 
I - Administração Direta: Presidência da República e Ministérios (art. 4ํ, I, do Dec.-lei $\mathrm{n}^{\circ}$ 200/67) ; Órgão de Assessoramento Imediato do Presidente da República (art. 32 do Dec.-lei n' 200/67); Órgãos Ad= ministrativos Parajudiciais (arts. 70 e 72 da Constituição da Repúblicá e outros dispositivos da legislação complementar e ordinária); Procuradorias (arts. 94 a 96 da Constituição da República e outros dispositivos da legislação ordinária); ôrgãos Autônomos (art. 172 do Dec.-lei $\mathrm{n}^{\circ}$ 200/67, com a redação dada pelo Dec.-lei $\mathrm{n}^{\circ}$ 900/69);

II - Administragão Indireta: autarquias, empresas públicas e sociedades de economia mista (art. 4º, II, do Dec.-lei $n^{\circ} 200 / 67$ );

III - Entes Legalmente excedentes da Administração Direta e da Indireta: fundações públicas art. $3^{\circ}$ do Dec.-lei $n^{\circ}$ 900/69; corporacões públicas de profissões liberais (Dec.-lei $\mathrm{n}^{\circ}$ 968, de 13-10-69); entidades e organizações de serviço-social, com contribuições parafiscais (art. 183 do Dec.-lei $\mathrm{n}^{\circ}$ 200/67).

Em nossa obra Servicos Comerciais, Industriais e Internacionais do Estado (1985, São Paulo, RT, p. 147-148), propusemos, de lege ferenda, estudo sobre eventual alteração na legislação federal brasileira, especialmente no Decreto-lei federal n* 200/67 e legislação subseqüente, no sentido de legiferar-se a seguinte estruturação da Administração Pública Federal Brasileira:

a) Administração Direta ou Centralizada: Presidência da República e Ministérios, órgãos de Assessoramento Imediato do Presidente da República; Órgãos Administrativos Parajudiciais; Procuradorias;

b) Administração Indireta ou Descentralizada: autarquias; entidades concessionárias, permissionárias, autorizadas e delegatárias;

c) Administração Infradireta ou Pericêntrica: empresas públicas; sociedades de economia mista; autarquias industriais; fundações públicas de profissões liberais; entidades e organizações de serviço público-social, com contribuições parafiscais; órgãos autônomos.

Definimos Administração Infradireta ou Pericêntrica como a atividade administrativa pública, sistemática, atípica, de participação materialmente coordenada do Estado no planejamento e manutençâo integrada do equilíbrio sócio-econômico, interno e internacional (cf. nosso Servicos Comerciais, Industriais e Internacionais do Estado, 1985, São Paulo, RT, p. 55).

Combinando-se nossa definição de Administração Internacional do Estado (cf. item 4.1 deste artigo) com o perfil institucional atual da Administração Pública Federal do Brasil, evidencia-se que as atividades e relações jurídico-administrativas de integração interestatal realizam-se, por excelência, pela Administração Direta (Presidência da República e Ministérios, sobretudo Ministério das Relações Exteriores) e, por exceção, pela Administração Indireta, assim como por fundações públicas. Todavia, considerando-se aquela estruturaçäó, proposta de lege ferenda, a Administração Internacional do Estado seria exercida pela Administração Direta ou Centralizada, por exceção, e pela Ad- 
ministração Infradireta ou Pericêntrica, em regra, com exclusão da Administração Indireta ou Descentralizada.

\section{4 - Relações Administrativas com a Administração Internacional.}

Definimos Administração Internacional como o complexo orgânicooperativo, autocoordenado, de manutenção das entidades internacionais e satisfação às necessidades e interesses públicos da comunidade internacional, mediante prestação direta de serviços aos indivíduos e aos Estados ou coordenação de serviços (cf. item 1 deste artigo e nosso Servicos Comerciais, Industrias e Internacionais do Estado, 1985, São Paulo, RT, p. 72). Nesta obra, à p. 131, definimos serviço administrativo integrante do Estado como a atividade atípica da administração, cujo objeto é a gestão da coordenação estatal e interestatal, para preservação do equilíbrio intra-sistêmico e preenchimento de lacunas técnico-científicas do serviço público estatal, mediante relações administrativas internas e internacionais, qualificadas pela interiorização mediata do fim de utilidade pública e imediata do interesse público internacional.

No tocante à área internacional, visa o serviço administrativo integrante do Estado a inserção coordenada (emissiva e receptiva) da Administração Pública interna na Administração Internacional, a interligação do serviço público interno com o serviço público internacional. Não se trata de juridicização de volições e opções políticas de Estados soberanos, matéria típica do Direito Internacional Público (ou da efi-cácia extraterritorial da potestade estatal, matéria de Direito Internacional Privado), mas da juridicização coordenante (em regra) ou subordinante (por exceção) de relações administrativas internacionais, cujo objeto é a transmissão de elementos técnico-científicos e cuja finalidade é a satisfação do interesse público internacional, não necessariamente coincidente com interesses públicos estatais particularizados.

\section{5. - Conclusões.}

Em vista do exposto, podem-se sintetizar as seguintes conclusões:

$\left.1^{\text {a }}\right)$ - o relacionamento administrativo internacional do EstadoAdministração, na área internacional, insere-se no âmbito da Administração Infradireta ou Pericêntrica, como Administração Interestatal; nos aspectos principiológico e de regime jurídico, subsume-se a duas disciplinas jurídicas - Direito Administrativo e Direito Internacional Público;

$2^{\text {a) }}$ - a autonomia científica das disciplinas jurídicas constitui uma construção teorética in fieri, em evolução lentíssima, mas perpétua e inexorável, cujo único aspecto sólido e definitivo consiste na possibilidade de alteração;

$3^{\text {a) }}$ - as áreas de Direito do Estado e de Direito Internacional aproximam-se, sob aspectos teórico e prático; 
$4^{\mathrm{a}}$ ) - a autonomia científica do Direito Administrativo e do Direito Internacional Público provém de ambas as disciplinas jurídicas fundamentarem-se em objetos próprios, métodos próprios e princípios informativos próprios;

5a) - na Ciência do Direito, assinala-se a existência de vários objetos interdisciplinares, consistentes de fatos do mundo ou de categorias jurídicas que, no mundo do Direito, são valorados, normatizados e recebem atributos diferenciais no âmbito próprio de duas ou mais disciplinas jurídicas;

$6^{a}$ ) - verifica-se a crescente interconexão entre o Direito Administrativo e o Direito Internacional Público; a área comum a ambas as disciplinas jurídicas dilata-se e solidifica-se de modo irreversivel, como resultado da montante integração administrativa internacional (cf. nosso Servicos Comerciais, Industriais e Internacionais do Estado, 1985, São Paulo, RT, p. 68-74 e 124-131);

$7^{\text {a }}$ ) - na literatura administrativista brasileira, a relevância da interconexão entre o Direito Administrativo e o Direito Internacional Público foi realçada, pela primeira vez, por José Cretella Júnior, em 1966, em seu Tratado de Direito Administrativo, vol. I, 1966, Rio/São Paulo, Forense, p. 195-196;

$8^{\text {a }}$ - há um objeto interdisciplinar, entre o Direito Administrativo e o Direito Internacional Público, consistente no serviço público estatal com destinação internacional e no serviço público internacional com destinação estatal, além de áreas específicas do Direito Internacional Público que aplicam Direito Administrativo (sobretudo Direito Administrativo Disciplinar) e áreas do Direito Administrativo que aplicam o Direito Internacional Público e, por exceção, o Direito do Comércio Internacional (de natureza privatística);

$9^{\text {a) }}$ - consideramos o Direito Administrativo Internacional como o capítulo do Direito Administrativo que rege juridicamente o serviço público-administrativo integrante do Estado, com destinação internacional; e consideramos o Direito Internacional Administrativo como o capítulo do Direito Internacional Público que rege juridicamente a atividade administrativa internacional, tanto a relativa à organização interior dos órgãos e entidades internacionais, como a dirigida à coordenação de serviços públicos estatais: embora ainda constituam capítulos de duas disciplinas jurídicas tradicionais (Direito Administrativo e Direito Internacional Público), ambos já regem objeto interdisciplinar comum, têm métodos virtualmente idênticos e conectam-se por um princípio setorial comum, o princípio da integração sistêmica da Administração;

10 $0^{a}$ - a análise do Direito Administrativo Internacional e do Direito Internacional Administrativo remanescerá sempre fundamentada numa aplicação especial do Direito Comparado, do método comparativo, ainda inaplicado à matéria;

11: - define-se Administracão Internacional do Estado como o conjunto de entidades, órgãos e agentes públicos estatais que concre- 
tizam as atividades e relações jurídico-administrativas de integração interestatal;

12a) - a Administração Internacional do Estado consiste em objeto interdisciplinar, cujo regime jurídico assenta-se nos métodos próprios e princípios informativos próprios do Direito Administrativo e do Direito Internacional Público.

13a) - na atual estruturação da Administração Pública Federal Brasileira, as atividades e relações jurídico-administrativas de integração interestatal realizam-se, pela Administração Direta (Presidência da República e Ministérios), e, por exceção, pela Administração Indireta, assim como por fundações públicas; todavia, de lege ferenda, a Administração Internacional do Estado seria exercida pela Administração Direta ou Centralizada, por exceção, e pela Administração Infradireta ou Pericêntrica, em regra, com exclusão da Administração Indireta ou Descentralizada.

14ª - a interligação da Administração Internacional do Estado com a Administração Internacional realiza-se por meio de relações administrativas internacionais, cujo objeto é a transmissão de elementos técnico-científicos e cuja finalidade é a satisfação do interesse público internacional, não necessariamente coincidente com interesses públicos estatais particularizados.

A guisa de fecho, esclarece-se que o presente tema, neste artigo, foi apenas suscitado, aflorado, em linhas gerais, pois se trata de matéria que exigiria uma alentada monografia. Por motivos ignotos, tal monografia ainda não existe, no Brasil, embora este País já conte com uma tradição de notáveis administrativistas e internacionalistas. Como já se frisou, trata-se de obra que precisa ser escrita, com a possível brevidade, atentando-se à observação de José Cretella Júnior: «cabe, com efeito, ao Direito Comparado, reivindicar para a ciência jurídica o caráter de universalidade que ela deve ter, sem o que o Direito não passará de um conjunto de pesquisas empíricas, de um casuísmo utilitarista a dirimir litígios imediatistas, à medida que ocorrerem, e não, como devera ser, o termostato da sociedade, a arte de dirigir os agrupamentos humanos e de regular as relações jurídicas entre sujeitos de direito, de acordo com o ideal supremo de justiça» (José Cretella Júnior, Administração Indireta Brasileira, Rio de Janeiro, Forense, 1980, p. 83, e Direito Administrativo Comparado, São Paulo, EDUSP, 1972, p. 12).

Na Faculdade de Direito da Universidade de São Paulo, o estudo desse objeto interdisciplinar poderá, agora ou no futuro, enquadrar-se nos Departamentos de Direito do Estado e de Direito Internacional (e nos respectivos Institutos) ou até num Centro Interdepartamental (art. 54 do Estatuto da USP, Decreto estadual n 52.326/69; art. 69 do Regimento Geral da USP, Decreto estadual no 52.906/72). Como já disse um ex-Ministro da Justiça do Brasil (Dr. Armando Falcão), «o futuro a Deus pertence». .

São Paulo, 03 de setembro de 1985. 